\title{
The effects of cement fixation on survival in elderly patients with hip hemiarthroplasty: a nationwide cohort study
}

\author{
Ming-Che Tsai ${ }^{1}$, Yee-Yung $\mathrm{Ng}^{2}$, Wei-Ming Chen ${ }^{3}$, Shang-Wen Tsai ${ }^{4}$ and Shiao-Chi Wu${ }^{5^{*}}$ (B)
}

\begin{abstract}
Background: Hip hemiarthroplasty $(\mathrm{HHA})$ is a common treatment for hip fractures in the elderly population. Because of the fatal effects of bone cement implantation syndrome, the safety of cement utilization to enhance implant firmness in the femur is controversial. The aim of this study was to investigate the postoperative survival of elderly patients receiving HHA with and without cement fixation.

Methods: Claim data from the National Health Insurance Database and the National Register of Deaths Database were used for analysis in this retrospective cohort study. From 2008 to 2014, 25,862 patients aged 80 years or older treated with hip hemiarthroplasty were included in the analysis. A Cox proportional risk model was used to analyse the effects of cement utilization on postoperative mortality.

Results: The cemented group had a significantly higher mortality risk than the non-cemented group within 7, 30, 180 days and 1 year after the operation. The effect of bone cement on postoperative mortality was significantly stronger within 7 days than within 30,180 days and 1 year. In addition, the male gender, age $>85$ years and higher score on the Charlson Comorbidity Index were also risk factors for mortality $(p<0.05)$. Patients who received HHA in lower-volume hospitals had higher mortality rates within 180 days and 1 year than those in higher-volume hospitals. Compared with patients who were operated on by high-volume surgeons, those who received surgery performed by lower-volume surgeons were more likely to die within 30 days (aHR $=1.22), 180$ days $(a H R=1.16)$ and 1 year (aHR=1.19), respectively.
\end{abstract}

Conclusions: The postoperative mortality rate of elderly patients undergoing HHA was significantly higher in the cemented group than in the non-cemented group.

Keywords: Cement, Elderly patient, Hip hemiarthroplasty, Postoperative survival

\section{Background}

In light of the increased number of hip fractures in the elderly above 80 years old, hip arthroplasty is an important issue in this population. Compared with total hip arthroplasty (THA), hip hemiarthroplasty (HHA) is a surgical procedure that is simpler and cheaper and yields fewer

* Correspondence: scwu@ym.edu.tw

${ }^{5}$ Institute of Health and Welfare Policy, College of Medicine, National Yang-Ming University, No.155, Sec.2, Linong Street, Taipei 11221, Taiwan, Republic of China

Full list of author information is available at the end of the article postoperative complications [1]; moreover, HHA is suitable for patients with displaced femoral neck fractures [2,3].

Although uncemented HHA has advantages such as a shorter operation time and less bleeding during the procedure [4], cemented HHA might still be performed based on the patient's age and bone mineral density, the surgeon's training, and the management of rehabilitation protocols $[5,6]$. Nonetheless, the toxic effects of bone cement might increase the risk of cardiopulmonary collapse $[4,7]$, and fatal bone cement implantation syndrome (BCIS) [8]. However, there is no consensus in recent studies on the postoperative mortality of patients who received bone 
cement [9-15]. The lack of consensus may be related to the fact that most of the previous studies were limited to a single institution, had a small sample size or used limited variables considered in database research. Therefore, the purpose of this study was to use a nationwide claims database to investigate the postoperative survival of elderly patients undergoing HHA with different fixation methods.

\section{Methods \\ Settings}

This retrospective cohort study used claims data during the period of 1 January 2007-31 December 2015 from the National Health Insurance Database (NHID) and the National Register of Deaths Database (NRDD) for analysis. Based on the NHID, patients who were aged 80 years or older and diagnosed with femoral neck fracture (International Classification of Diseases, Ninth Revision, Clinical Modification (ICD-9-CM) codes: 820.xx) between January 1, 2008, and December 31, 2014, and were treated with HHA (ICD-9-CM procedure codes: 81.52 ) were eligible for inclusion $(n=26,247)$. The patients who underwent THA (ICD-9-CM procedure codes: 81.51), HHA, or revision of hip replacement (ICD-9-CM procedure codes: 81.53) during hospitalization $(n=24)$ or one year prior to hospitalization $(n=361)$ were excluded from this study. Finally, 25,862 cases were included in the analysis.

\section{Data collection}

The National Health Insurance programme in Taiwan has included over $99.7 \%$ of the Taiwanese population since 2004 and provides universal, compulsory coverage with low co-payments to minimize the economic barrier to care for patients needing inpatient, outpatient, prescription, and other services. The NHID contains each patient's demographic characteristics, medical treatment location and detailed records of outpatient visits, hospital admissions, and emergency department (ED) visits, including diagnoses, procedures, medications, providers, and expenses [16]. The NRDD monitors the completeness and accuracy of death registration data retrieved from the Ministry of Health and Welfare, and the data contained age, sex, date of death, and causes of death. Both databases are encrypted, patient data are de-identified, and the database is monitored for completeness and accuracy by Taiwan's Ministry of Health and Welfare. The authors analysed data at the Health and Welfare Data Science Centre, which is an independent workplace managed by Taiwan's Ministry of Health and Welfare.

The dependent variable of this study was all-cause mortality within 1 year after the operation. The duration from the first day of hospitalization to the day of death was defined as the overall survival time. Subjects who were still alive after 1 year of follow-up were censored.
The fixation method (cemented or uncemented) was the main independent variable in this study and was identified by payment codes from the Taiwan NHI Medical Service Benefits and Payment Criteria [17]. Other covariates included characteristics of patients and healthcare providers. The patients' characteristics included sex, age group (80-84 years, $85-89$ years, $\geq 90$ years), insurance status ( $\geq 840$ USD, $<840$ USD) [18], Charlson comorbidity index $(\mathrm{CCI})$ status $(\mathrm{CCI}=0, \mathrm{CCI} \geq 1)$ during the last year before the operation [19-21] and type of head used in the operation (unipolar hemiarthroplasty (UHA) or bipolar hemiarthroplasty (BHA)) [22-25]. The insurance premiums were determined by the enrolee's income and therefore were a proxy for income status [26]. Insurance status was classified into two groups according to the median of the insurance premiums.

The providers' characteristics included the type of hospital (private (including corporate) or public hospital) $[27,28]$, hospital accreditation level (medical centre, non-medical centre) [28], the annual volumes of hip replacement for the hospital [29-33] and surgeon [29, 30, 34]. Annual volumes of hip replacement were classified into two groups according to the median operation case number among all the providers/surgeons.

\section{Statistical analysis}

Pearson's $\chi 2$ test was used to compare characteristics between the study participants who received cement and those who did not. The log-rank test was used to compare the mortality rates of different time intervals $(7,30,180$ days and 1 year from the operation) between participants receiving cement and noncement HHA. To assess the one-year mortality risk factors of different fixation methods, we fitted a Cox proportional hazard regression with covariates including sex, age group, insurance status, CCI score, hospital type, hospital level, hospital volume, and surgeon volume. We also investigated multicollinearity by the variance inflation factor (VIF) using regression analysis. Because the VIF of each coefficient was less than 5, we presumed that the effect of correlation among the independent variables was not enough to distort the estimation. For data management and statistical analysis, we used the statistical software SAS 9.4 (SAS Institute, Inc., Cary, North Carolina, USA).

\section{Ethics and conflict of interest}

This study was approved by the Institutional Review Board of National Yang-Ming University in Taiwan (approval number YM105043E-3). The authors declare no any financial and non-financial competing interests.

\section{Results}

The basic characteristics of patients who received HHA In total, $47.8 \%(12,364)$ of patients received cemented HHA. The percentages of female patients, patients with age $\geq 90$ years, patients with lower insurance premiums, patients receiving UHA, patients treated at higher-volume 
hospitals, and patients operated on by higher-volume surgeons were significantly higher in the cemented HHA group than in the uncemented HHA group. The CCI score was not significantly different between the two groups (Table 1).

\section{Postoperative mortality of elderly patients undergoing HHA}

As shown in Table 2, the overall postoperative mortality rates within $7,30,180$ days and 1 year among senior patients who received HHA were $0.6,3.1,11.2$, and $17.3 \%$, respectively. The mortality rates at 7 days $(0.7 \%$ vs $0.4 \%$, $p<0.01), \quad 30$ days $(3.5 \%$ vs $2.7 \%, p<0.01), 180$ days $(11.8 \%$ vs $10.7 \%, p<0.01)$ and 1 year $(18.0 \%$ vs $16.7 \%$, $p<0.01)$ were significantly higher in the cement group than in the non-cement group.

\section{Risk factors for mortality in elderly patients receiving HHA}

Tables 3 and 4 present the crude and adjusted hazard ratios of risk factors of mortality within 7, 30, 180 days and 1 year. The patients who received bone cement had

Table 1 Description of elderly patients undergoing hip hemiarthroplasty

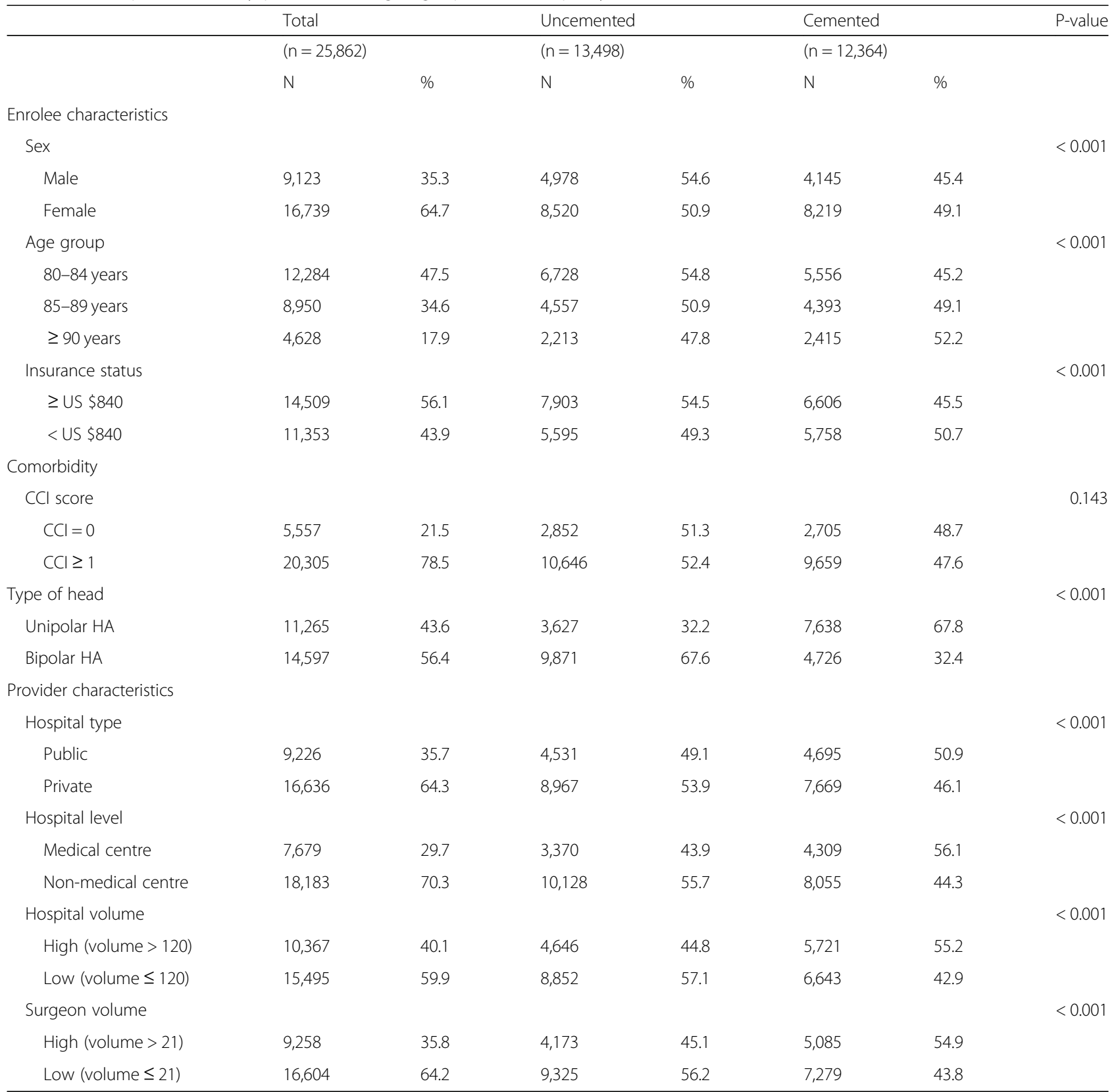

Note: Distribution among groups was analysed by the $x^{2}$-square test 
Table 2 Postoperative mortality of elderly patients undergoing hip hemiarthroplasty

\begin{tabular}{|c|c|c|c|c|c|c|c|c|c|}
\hline & Total & $7-d \bar{c}$ & & $30-c$ & & $180-$ & & 1-yea & \\
\hline & $\mathrm{N}$ & $\%$ & P & $\%$ & $P$ & $\%$ & P & $\%$ & P \\
\hline All & 25,862 & 0.6 & & 3.1 & & 11.2 & & 17.3 & \\
\hline Fixation method & & & 0.001 & & $<0.001$ & & 0.003 & & 0.005 \\
\hline Cemented & 12,364 & 0.7 & & 3.5 & & 11.8 & & 18.0 & \\
\hline Uncemented & 13,498 & 0.4 & & 2.7 & & 10.7 & & 16.7 & \\
\hline Gender & & & 0.013 & & $<0.001$ & & $<0.001$ & & $<0.001$ \\
\hline Male & 9,123 & 0.7 & & 4.2 & & 15.2 & & 23.3 & \\
\hline Female & 16,739 & 0.5 & & 2.5 & & 9.1 & & 14.1 & \\
\hline Age Group & & & 0.002 & & $<0.001$ & & $<0.001$ & & $<0.001$ \\
\hline $80-84$ years & 12,284 & 0.4 & & 2.2 & & 8.8 & & 14.2 & \\
\hline $85-89$ years & 8,950 & 0.7 & & 3.3 & & 11.9 & & 18.1 & \\
\hline$\geq 90$ years & 4,628 & 0.8 & & 4.9 & & 16.2 & & 24.1 & \\
\hline Insurance status & & & 0.468 & & 0.054 & & 0.220 & & 0.066 \\
\hline$\geq$ US $\$ 840$ & 14,509 & 0.6 & & 3.3 & & 11.4 & & 17.7 & \\
\hline$<$ US $\$ 840$ & 11,353 & 0.5 & & 2.9 & & 10.9 & & 16.8 & \\
\hline CCl score & & & 0.229 & & $<0.001$ & & $<0.001$ & & $<0.001$ \\
\hline $\mathrm{CCl}=0$ & 5,557 & 0.5 & & 2.2 & & 12.2 & & 18.7 & \\
\hline $\mathrm{CCl} \geq 1$ & 20,305 & 0.6 & & 3.3 & & 15.2 & & 23.3 & \\
\hline Type of head & & & 0.131 & & 0.417 & & 0.365 & & 0.033 \\
\hline UHA & 11,265 & 0.7 & & 3.2 & & 11.4 & & 17.9 & \\
\hline $\mathrm{BHA}$ & 14,597 & 0.5 & & 3.0 & & 11.1 & & 16.9 & \\
\hline Hospital type & & & 0.842 & & 0.584 & & 0.328 & & 0.022 \\
\hline Public & 9,226 & 0.6 & & 3.2 & & 11.5 & & 18.0 & \\
\hline Private & 16,636 & 0.6 & & 3.1 & & 11.1 & & 16.9 & \\
\hline Hospital level & & & 0.964 & & 0.213 & & 0.003 & & 0.004 \\
\hline Medical centre & 7,679 & 0.6 & & 2.9 & & 10.3 & & 16.3 & \\
\hline Non-medical centre & 18,183 & 0.6 & & 3.2 & & 11.6 & & 17.7 & \\
\hline Hospital volume & & & 0.428 & & 0.184 & & $<0.001$ & & $<0.001$ \\
\hline High (> 120) & 10,367 & 0.5 & & 2.9 & & 10.2 & & 16.0 & \\
\hline Low $(\leq 120)$ & 15,495 & 0.6 & & 3.2 & & 11.9 & & 18.2 & \\
\hline Surgeon volume & & & 0.360 & & 0.015 & & $<0.001$ & & $<0.001$ \\
\hline High $(>21)$ & 9,258 & 0.5 & & 2.7 & & 10.2 & & 15.6 & \\
\hline $\operatorname{Low}(\leq 21)$ & 16,604 & 0.6 & & 3.3 & & 11.8 & & 18.3 & \\
\hline
\end{tabular}

Note: Distribution among groups was analysed by the log-rank test

a significantly higher mortality risk than those who did not receive bone cement within $7,30,180$ days and 1 year $(\mathrm{aHR}=1.8,95 \% \mathrm{CI}=1.23-2.51, p<0.01$; $\mathrm{aHR}=1.4$, 95\% CI $=1.17-1.58, p<0.01 ;$ aHR $=1.2,95 \% \mathrm{CI}=1.08-$ $1.26, p<0.01 ; \mathrm{aHR}=1.1,95 \% \mathrm{CI}=1.04-1.18, p<0.01$ ), respectively. The type of head and insurance status were not risk factors for mortality $(p>0.05)$. Male gender and age $>85$ years were risk factors for mortality within 7 , 30,180 days and 1 year $(p<0.05)$. CCI scores were identified as a significant risk factor for 30 days, 180 days and 1 -year mortality $(p<0.05)$. After adjustment, hospital type and hospital level were not risk factors for mortality $(p>0.05)$ (Table 4). Patients who received HHA at lower-volume hospitals were 1.16 and 1.15 times more likely to die within 180 days and 1 year than those who received HHA at high-volume hospitals $(95 \% \mathrm{CI}=1.05$ $1.29, p<0.01 ; 95 \% \mathrm{CI}=1.06-1.24, p<0.01)$, respectively (Table 4). Compared with patients who were operated on by high-volume surgeons, those who were operated on by lower-volume surgeons were more likely to die within 30 days $(\mathrm{aHR}=1.22,95 \% \mathrm{CI}=1.05-1.42, \quad p<$ $0.05), 180$ days $(\mathrm{aHR}=1.16,95 \% \mathrm{CI}=1.07-1.25, p<0.01)$ 
Table 3 Risk factors for 7-day, 30-day, 180-day and 1-year mortality using Cox regression analysis with crude hazard ratios (cHRs) and $95 \%$ confidence intervals (Cls)

\begin{tabular}{|c|c|c|c|c|c|c|c|c|c|c|c|c|}
\hline & & 7 days & & & 30 days & & & 180 days & & & 1 year & \\
\hline & $\mathrm{CHR}$ & $(95 \% \mathrm{Cl})$ & $P$ & $\mathrm{CHR}$ & $(95 \% \mathrm{Cl})$ & $P$ & $\mathrm{cHR}$ & $(95 \% \mathrm{Cl})$ & $P$ & $\mathrm{CHR}$ & $(95 \% \mathrm{Cl})$ & $P$ \\
\hline \multicolumn{13}{|c|}{ Fixation method (Ref: Uncemented) } \\
\hline Cemented & 1.72 & $1.23-2.39$ & 0.001 & 1.29 & $1.12-1.48$ & $<0.001$ & 1.12 & $1.04-1.20$ & 0.003 & 1.08 & $1.02-1.15$ & 0.007 \\
\hline \multicolumn{13}{|l|}{ Gender (Ref: Female) } \\
\hline Male & 1.50 & $1.09-2.07$ & 0.014 & 1.67 & $1.45-1.92$ & $<0.001$ & 1.73 & $1.61-1.86$ & $<0.001$ & 1.76 & $1.66-1.86$ & $<0.001$ \\
\hline \multicolumn{13}{|c|}{ Age group (Ref: $80-84$ years) } \\
\hline $85-89$ years & 1.68 & $1.15-2.44$ & 0.007 & 1.48 & $1.26-1.74$ & $<0.001$ & 1.39 & $1.27-1.51$ & $<0.001$ & 1.30 & $1.22-1.39$ & $<0.001$ \\
\hline$\geq 90$ years & 2.02 & $1.33-3.08$ & 0.001 & 2.23 & $1.87-2.66$ & $<0.001$ & 1.94 & $1.76-2.13$ & $<0.001$ & 1.82 & $1.69-1.96$ & $<0.001$ \\
\hline \multicolumn{13}{|c|}{ Insurance status (Ref: $\geq$ US \$840) } \\
\hline$<$ US $\$ 840$ & 0.89 & $0.64-1.23$ & 0.468 & 0.87 & $0.76-1.00$ & 0.054 & 0.96 & $0.89-1.03$ & 0.221 & 0.95 & $0.90-1.01$ & 0.077 \\
\hline \multicolumn{13}{|l|}{ CCl score (Ref: $\mathrm{CCl}=0$ ) } \\
\hline $\mathrm{CCl} \geq 1$ & 1.30 & $0.85-1.98$ & 0.231 & 1.53 & $1.26-1.86$ & $<0.001$ & 1.62 & $1.46-1.79$ & $<0.001$ & 1.57 & $1.45-1.70$ & $<0.001$ \\
\hline \multicolumn{13}{|l|}{ Type of head (Ref: BHA) } \\
\hline UHA & 1.28 & $0.93-1.11$ & 0.133 & 1.06 & $0.92-1.22$ & 0.416 & 1.04 & $0.96-1.11$ & 0.364 & 1.07 & $1.01-1.13$ & 0.034 \\
\hline \multicolumn{13}{|c|}{ Hospital type (Ref: Private) } \\
\hline Public & 0.97 & $0.69-1.35$ & 0.843 & 1.04 & $0.90-1.20$ & 0.582 & 1.04 & $0.96-1.12$ & 0.326 & 1.07 & $1.01-1.13$ & 0.034 \\
\hline \multicolumn{13}{|c|}{ Hospital level (Ref: Medical centre) } \\
\hline Non-medical centre & 1.01 & $0.71-1.43$ & 0.964 & 1.10 & $0.95-1.29$ & 0.214 & 1.13 & $1.05-1.23$ & 0.003 & 1.11 & $1.04-1.18$ & 0.002 \\
\hline \multicolumn{13}{|c|}{ Hospital volume (Ref: High) } \\
\hline Low & 1.14 & $0.82-1.60$ & 0.428 & 1.10 & $0.96-1.27$ & 0.185 & 1.18 & $1.10-1.28$ & $<0.001$ & 1.15 & $1.09-1.23$ & $<0.001$ \\
\hline \multicolumn{13}{|c|}{ Surgeon volume (Ref: High) } \\
\hline Low & 1.17 & $0.83-1.60$ & 0.362 & 1.20 & $1.04-1.40$ & 0.015 & 1.17 & $1.08-1.26$ & $<0.001$ & 1.20 & $1.13-1.27$ & $<0.001$ \\
\hline
\end{tabular}

and 1 year $(\mathrm{aHR}=1.19,95 \% \mathrm{CI}=1.12-1.27, \quad p<0.01)$. The effect of bone cement on postoperative mortality was significantly stronger within 7 days than within 30 , 180 days and 1 year (Table 5).

\section{Discussion}

To the best of our knowledge, this is the first study using nationwide claim data to evaluate the effect of the HHA fixation method on survival in elderly patients. It is worth noting that the cemented group had a significantly higher mortality risk than the non-cemented group within 7,30 , 180 days and 1 year after the operation. The postoperative mortality effect of bone cement was significantly decreased after 7 days (Tables 3, 4 and 5). This finding might explain previous studies revealing that cement has different impacts according to different postoperative follow-up periods $[9,12]$. The cement group had significantly higher mortality within 7 days but no difference after 30 days (Table 5). In other words, the mortality risk correlated with the usage of cement mainly occurred in the first 7 days after surgery. Thus, the higher mortality in the cement group might be associated with potentially fatal complications of BCIS $[35,36]$.
The previous literature showed that the provider's experience and volume remained an important factor for postoperative survival in different kinds of operations, including eye surgery, coronary artery bypass graft, HHA and total hip replacement [29-34, 37, 38]. These studies further support our findings that patients treated at high-volume hospitals and by high-volume surgeons had a lower risk. Hospitals and surgeons with a high volume of cases may have more experience to avoid mistakes, resulting in fewer adverse consequences and complications [29-34].

In our study, male gender, older age and higher score on the comorbidity index $(\mathrm{CCI} \geqq 1)$ were the independent determinants of increased mortality, which were also consistent with other studies [11, 20, 22-24, 30, 39, 40]. Because the degree of biological ageing significantly affects changes in body tissue structure and dysfunction, older patients are prone to have medical complications and higher mortality rates. Patients with high $\mathrm{CCI}$ values may have various kinds of comorbidities or even more severe conditions, such as COPD [18, 40,41], cognitive impairment $[11,18]$ and heart disease $[18,35,40]$, which may affect postoperative mortality. The higher mortality rates in men than in women may be related to their lower 
Table 4 Risk factors for 7-day, 30-day, 180-day and 1-year mortality using Cox regression analysis with adjusted hazard ratios (aHRs) and $95 \%$ confidence intervals (Cls)

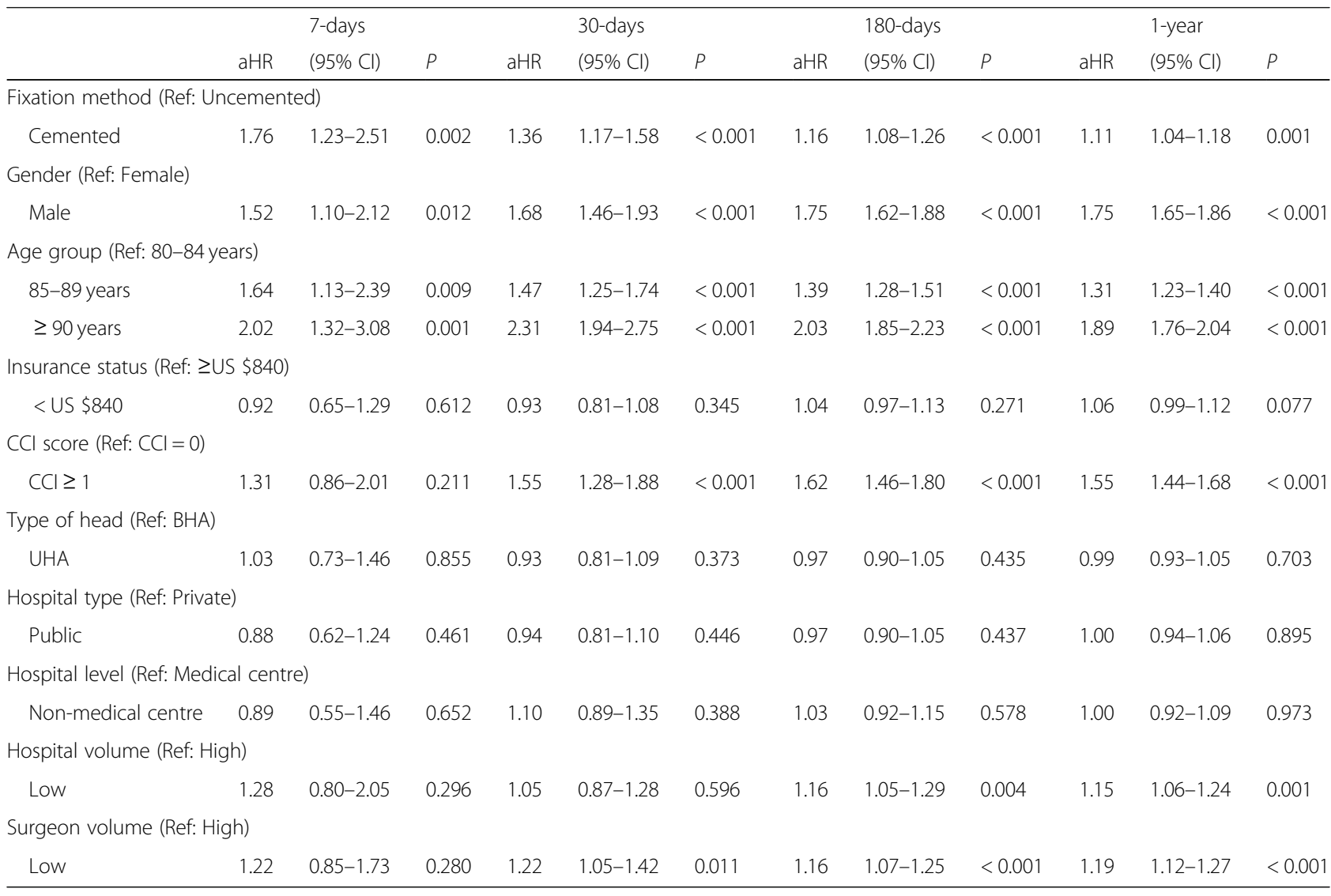

ability of self-care, which may also result in the occurrence of more complications or even lead to death [41].

Although the large amount of administration data in the NHID could avoid sampling bias, the main purpose of the NHID is to apply for medical insurance expenditure. Clinical data such as clinical notes, operational procedures, disease severity, and radiological images were lacking as other administration datasets. Other potential risk factors of mortality, such as surgical time, surgical methods, material characteristics such as type of stem [42-44], BMI [45], walking ability [46], disease severity $(11,40)$, self-care ability and strength of family support $[47,48]$, may not be documented in the NHID. Many observational variables were adjusted in this study, and Taiwanese research [23] has revealed that the activities of daily living (ADL) and the American Society of Anesthesiologists (ASA) Classification scores have no significant effects on survival outcomes. This study can only be considered regarding the influence of medical care but cannot be extended to explain the factors related to family care and that may affect postoperative survivorship. However, our study used the characteristics of medical care providers, including hospitals and surgeons, as alternative variables to decrease the possible influence of the potential risk factors of mortality $[11,31,46]$.

Table 5 Effect of bone cement on postoperative mortality in elderly survivors undergoing hip arthroplasty

\begin{tabular}{|c|c|c|c|c|c|c|c|c|c|}
\hline & \multicolumn{3}{|c|}{7 days to 1 year } & \multicolumn{3}{|c|}{30 days to 1 year } & \multicolumn{3}{|c|}{180 days to 1 year } \\
\hline & Event & $\%$ & $P$ & Event & $\%$ & $P$ & Event & $\%$ & $P$ \\
\hline All & 4,327 & 16.8 & & 3,675 & 14.7 & & 1,577 & 6.9 & \\
\hline Fixation method & & & 0.024 & & & 0.157 & & & 0.452 \\
\hline Cemented & 2,130 & 17.4 & & 1,788 & 15.0 & & 763 & 7.0 & \\
\hline Uncemented & 21,97 & 16.3 & & 1,887 & 14.4 & & 814 & 6.8 & \\
\hline
\end{tabular}

Note: 1 . the survivors in the first $7,30,180$ days were followed up to 1 year for postoperative mortality

2. Distribution among groups was analysed by the log-rank test 


\section{Conclusion}

The postoperative mortality in elderly patients with HHA was significantly higher in patients receiving cement, especially within 7 days. The higher mortality rates were also associated with higher CCI scores of the patient and lower operation volumes of the hospitals and surgeons.

\section{Abbreviations}

95\% Cl: 95\% Confidence interval; AHR: Adjusted hazard ratio; BCIS: Bone cement implantation syndrome; BHA: Bipolar hemiarthroplasty; CCl: Charlson comorbidity index; HHA: Hip hemiarthroplasty; ICD-9-CM: International Classification of Diseases, 9th revision, Clinical Modification; THA: Total hip arthroplasty; UHA: Unipolar hemiarthroplasty

\section{Acknowledgements}

Not applicable.

\section{Authors' contributions}

MCT, YYN, and SCW designed the study and wrote the manuscript. MCT performed the data analysis. WMC and SWT provided clinical experience and participated in the writing and discussion of the manuscript. MCT and SCW supervised the entire study. All authors read and approved the final manuscript.

\section{Funding}

This study was supported by the Ministry of Science and Technology which is a government agency responsible for academic development in Taiwan (approval number MOST 107-2410-H-010-010-MY3). The Ministry of Science and Technology and Ministry of Health and Welfare in Taiwan for providing financial support and the data collection for this study. The conclusions in this study do not represent those of the Ministry of Science and Technology or Ministry of Health and Welfare.

\section{Availability of data and materials}

The data that support the findings of this study are available from the Ministry of Health and Welfare in Taiwan but restrictions apply to the availability of these data, which were used under license for the current study, and so are not publicly available. These databases were encrypted, deidentified and monitored for completeness and accuracy by the Ministry of Health and Welfare in Taiwan. Data are however available from the authors upon reasonable request and with permission of the Ministry of Health and Welfare.

\section{Ethics approval and consent to participate}

This study was approved by the Institutional Review Board of National YangMing University in Taiwan (approval number YM105043E-3). As this study is labelled as retrospective there is no need for consent to participate to be obtained, and it has been approved as an exempt research by the ethics committee.

\section{Consent for publication}

Not applicable.

\section{Competing interests}

The authors declare no any financial and non-financial competing interests.

\section{Author details}

${ }^{1}$ Institute of Health and Welfare Policy, School of Medicine, National Yang-Ming University, Taipei, Taiwan. ${ }^{2}$ Department of Medicine, Fu Jen Catholic University Hospital, Fu Jen Catholic University, New Taipei City, Taiwan. ${ }^{3}$ Department of Orthopaedics, Taipei Veterans General Hospital, School of Medicine, National Yang-Ming University, Taipei, Taiwan. ${ }^{4}$ Department of Orthopaedics, Taipei Veterans General Hospital, Taipei, Taiwan. ${ }^{5}$ Institute of Health and Welfare Policy, College of Medicine, National Yang-Ming University, No.155, Sec.2, Linong Street, Taipei 11221, Taiwan, Republic of China.
Received: 3 December 2019 Accepted: 18 December 2019

Published online: 27 December 2019

\section{References}

1. MPJvd B, Hilverdink EF, Sierevelt IN, EMBP R, Schnater JM, Bonke H, et al. A comparison of hemiarthroplasty with total hip replacement for displaced intracapsular fracture of the femoral neck: a randomised controlled multicentre trial in patients aged 70 years and over. The Journal of bone and joint surgery British volume. 2010;92(10):1422-8.

2. Rogmark C, Leonardsson O. Hip arthroplasty for the treatment of displaced fractures of the femoral neck in elderly patients. The bone \& joint journal. 2016;98-B(3):291-7.

3. Chammout G, Kelly-Pettersson P, Hedbeck C-J, Stark A, Mukka S, Sköldenberg O. HOPE-Trial: Hemiarthroplasty Compared with Total Hip Arthroplasty for Displaced Femoral Neck Fractures in Octogenarians: A Randomized Controlled Trial. JBJS Open Access. 2019;4(2):e0059-e.

4. $\mathrm{Ng}$ ZD, Krishna L. Cemented versus cementless hemiarthroplasty for femoral neck fractures in the elderly. Journal of orthopaedic surgery (Hong Kong). 2014;22(2):186-9.

5. Parker Ml, Pryor G, Gurusamy K. Cemented versus uncemented hemiarthroplasty for intracapsular hip fractures: a randomised controlled trial in 400 patients. Journal of bone and joint surgery British volume. 2010; 92(1):116-22.

6. Veldman HD, Heyligers IC, Grimm B, Boymans TAEJ. Cemented versus cementless hemiarthroplasty for a displaced fracture of the femoral neck: a systematic review and meta-analysis of current generation hip stems. The bone \& joint journal. 2017;99-B(4):421-31.

7. Pitto RP, Blunk J, Kößler M. Transesophageal echocardiography and clinical features of fat embolism during cemented total hip arthroplasty. A randomized study in patients with a femoral neck fracture. Arch Orthop Trauma Surg. 2000;120(1-2):53-8.

8. Singh V, Bhakta $P$, Zietak E, Hussain A. Bone cement implantation syndrome: a delayed postoperative presentation. J Clin Anesth. 2016;31:274-7.

9. Costain DJ, Whitehouse SL, Pratt NL, Graves SE, Ryan P, Crawford RW. Perioperative mortality after hemiarthroplasty related to fixation method: a study based on the australian orthopaedic association national joint replacement registry. Acta Orthop. 2011;82(3):275-81.

10. DeAngelis JP, Ademi A, Staff I, Lewis CG. Cemented versus uncemented hemiarthroplasty for displaced femoral neck fractures: a prospective randomized trial with early follow-up. J Orthop Trauma. 2012;26(3):135-40.

11. Leonardsson O, Kärrholm J, Åkesson K, Garellick G, Rogmark C. Higher risk of reoperation for bipolar and uncemented hemiarthroplasty. Acta Orthop. 2012;83(5):459-66

12. Talsnes $\mathrm{O}$, Vinje T, Gjertsen JE, Dahl OE, Engesæter LB, Baste $V$, et al. Perioperative mortality in hip fracture patients treated with cemented and uncemented hemiprosthesis: a register study of 11,210 patients. Int Orthop. 2013;37(6):1135-40.

13. Grammatopoulos G, Wilson HA, Kendrick BJL, Pulford EC, Lippett J, Deakin $M$, et al. Hemiarthroplasty using cemented or uncemented stems of proven design: a comparative study. The bone \& joint journal. 2015;97-B(1):94-9.

14. Fuchs M, Sass FA, Dietze S, KRÄMER M, PERKA C, Müller M. Cemented Hemiarthroplasties are associated with a higher mortality rate after femoral neck fractures in elderly patients. Acta Chir Orthop Traumatol Cechoslov. 2017:84(5):341-6.

15. Frenken MRM, Schotanus MGM, EHv H, Hendrickx R. Cemented versus uncemented hemiarthroplasty of the hip in patients with a femoral neck fracture: a comparison of two modern stem design implants. Eur J Orthop Surg Traumatol. 2018;28:1350-12.

16. Hsieh C-Y, Su C-C, Shao S-C, Sung S-F, Lin S-J, Yang Y-HK, et al. Taiwan's National Health Insurance Research Database: past and future. Clinical Epidemiology. 2019;11:349.

17. Administration NHI. Taiwan NHI Medical Service Benefits and Payment Criteria: National Health Insurance Administration Ministry of Health and Welfare; 2016 [updated 2019/04/17. Available from: http://www.nhi.gov.tw/ webdata/webdata.aspx?menu=20\&menu_id=710\&webdata_id=3633.

18. Hsu I-L, Chang C-M, Yang D-C, Chang Y-H, Li C-C, Hu SC, et al. Socioeconomic inequality in one-year mortality of elderly people with hip fracture in Taiwan. Int J Environ Res Public Health. 2018;15(2):352.

19. Romano PS, Roos LL, Jollis JG. Presentation adapting a clinical comorbidity index for use with ICD-9-CM administrative data: differing perspectives. J Clin Epidemiol. 1993;46(10):1075-9. 
20. Ong KL, Kurtz SM, Lau E, Bozic KJ, Berry DJ, Parvizi J. Prosthetic joint infection risk after total hip arthroplasty in the Medicare population. J Arthroplast. 2009;24(6 Suppl):105-9.

21. Chu YT, Wu SC. A review of claims-based comorbidity measures. Taiwan Journal of Public Health. 2010;29(1):8-21.

22. Sabnis BM, Brenkel IJ. Unipolar versus bipolar uncemented hemiarthroplasty for elderly patients with displaced intracapsular femoral neck fractures. Journal of orthopaedic surgery (Hong Kong). 2011;19(1):8-12.

23. Lin CC, Huang SC, Ou YK, Liu YC, Tsai CM, Chan HH, et al. Survival of patients aged over 80 years after Austin-Moore hemiarthroplasty and bipolar hemiarthroplasty for femoral neck fractures. Asian journal of surgery. 2012;35(2):62-6.

24. Ayhan E, Kesmezacar H, Karaman Ö, Şahin A, Kır N. Bipolar or unipolar hemiarthroplasty after femoral neck fracture in the geriatric population. Balkan medical journal. 2013:30(4):400-5.

25. Kanto K, Sihvonen R, Eskelinen A, Laitinen M. Uni- and bipolar hemiarthroplasty with a modern cemented femoral component provides elderly patients with displaced femoral neck fractures with equal functional outcome and survivorship at medium-term follow-up. Arch Orthop Trauma Surg. 2014;134(9):1251-9.

26. Tsai HY, Chou YJ, Pu C. Continuity of care trajectories and emergency room use among patients with diabetes. Int J Public Health. 2015;60(4):505-13.

27. Mnatzaganian G, Ryan P, Norman PE, Davidson DC, Hiller JE. Length of stay in hospital and all-cause readmission following elective total joint replacement in elderly men. Orthop Res Rev. 2012;43.

28. Lo YT, Chang GM, Tung YC. Impact of the DRG-based prospective payment system on medical utilization and outcomes of care for hip fracture and hip replacement. Taiwan Journal of Public Health. 2015;34(2):180-92.

29. Chien LN, Chu HF, Liu CH, Chung KP, Tsauo JY, Ng YY, et al. Association between hospital and surgeon procedure volume with outcome of Total hip replacement. Taiwan Journal of Public Health. 2003;22(2):118-26.

30. Shah SN, Wainess RM, Karunakar MA. Hemiarthroplasty for femoral neck fracture in the elderly surgeon and hospital volume-related outcomes. J Arthroplast. 2005;20(4):503-8.

31. Rogmark C, Fenstad AM, Leonardsson O, Engesæter LB, Kärrholm J, Furnes $\mathrm{O}$, et al. Posterior approach and uncemented stems increases the risk of reoperation after hemiarthroplasties in elderly hip fracture patients. Acta Orthop. 2014:85(1):18-25.

32. Metcalfe D, Salim A, Olufajo O, Gabbe B, Zogg C, Harris MB, et al. Hospital case volume and outcomes for proximal femoral fractures in the USA: an observational study. BMJ Open. 2016;6(4):e010743.

33. Clement RC, Strassle PD, Ostrum RF. Should all Orthopaedists perform Hemiarthroplasty for femoral neck fractures? A volume-outcome analysis. J Orthop Trauma. 2018;32(7):354-60.

34. Enocson A, Hedbeck CJ, Törnkvist H, Tidermark J, Lapidus $\sqcup$. Unipolar versus bipolar Exeter hip hemiarthroplasty: a prospective cohort study on 830 consecutive hips in patients with femoral neck fractures. Int Orthop. 2012;36(4):711-7.

35. Olsen F, Kotyra M, Houltz E, Ricksten S-E. Bone cement implantation syndrome in cemented hemiarthroplasty for femoral neck fracture: incidence, risk factors, and effect on outcome. Br J Anaesth. 2014;113(5):800-6.

36. Griffiths R, White SM, Moppett IK, Parker MJ, Chesser TJS, Costa ML, et al. Safety guideline: reducing the risk from cemented hemiarthroplasty for hip fracture 2015: Association of Anaesthetists of Great Britain and Ireland British Orthopaedic Association British geriatric society. Anaesthesia. 2015; 70(5):623-6.

37. Fang $Y-T$, Chien L-N, Ng Y-Y, Chu H-F, Chen W-M, Cheng C-Y, et al. Association of hospital and surgeon operation volume with the incidence of postoperative endophthalmitis: Taiwan experience. Eye. 2006;20(8):900.

38. Ng Y-Y, Hung Y-N, Wu S-C, Ko P-J. Characteristics and 3-year mortality and infection rates among incident hemodialysis patients with a permanent catheter undergoing a first vascular access conversion. Clin Exp Nephrol. 2014;18(2):329-38.

39. Wu SC, Chien LN, Ng YY. Using the comorbidity index to evaluate the medical utilization and outcomes of Total hip replacement through analyzing National Insurance Claimed Data. Taiwan J Public Health. 2004; 23(2):121-9.

40. Liodakis E, Antoniou J, Zukor DJ, Huk OL, Epure LM, Bergeron SG. Major Complications and Transfusion Rates After Hemiarthroplasty and Total Hip Arthroplasty for Femoral Neck Fractures. J Arthroplast. 2016;31(9):2008-12.

41. Lin JCF, Liang WM. Mortality, readmission, and reoperation after hip fracture in nonagenarians. BMC Musculoskelet Disord. 2017;18(1):144.
42. Mukka S, Mellner C, Knutsson B, Sayed-Noor A, Sköldenberg O. Substantially higher prevalence of postoperative periprosthetic fractures in octogenarians with hip fractures operated with a cemented, polished tapered stem rather than an anatomic stem. Acta Orthop. 2016;87(3):257-61.

43. Palan J, Smith M, Gregg P, Mellon S, Kulkarni A, Tucker K, et al. The influence of cemented femoral stem choice on the incidence of revision for periprosthetic fracture after primary total hip arthroplasty: an analysis of national joint registry data. The bone \& joint journal. 2016;98(10):1347-54.

44. Mohammed J, Mukka S, Hedbeck C-J, Chammout G, Gordon M, Sköldenberg $\mathrm{O}$. Reduced periprosthetic fracture rate when changing from a tapered polished stem to an anatomical stem for cemented hip arthroplasty: an observational prospective cohort study with a follow-up of 2 years. Acta Orthop. 2019:1-10.

45. Sayed-Noor AS, Mukka S, Mohaddes M, Kärrholm J, Rolfson O. Body mass index is associated with risk of reoperation and revision after primary total hip arthroplasty: a study of the Swedish hip Arthroplasty register including 83,146 patients. Acta Orthop. 2019:1-10.

46. Salem KMI, Shannak OA, Scammell BE, Moran CG. Predictors and outcomes of treatment in hip hemiarthroplasty dislocation. Ann R Coll Surg Engl. 2014 96(6):446-51.

47. Magaziner J, Hawkes W, Hebel JR, Zimmerman SI, Fox KM, Dolan M, et al. Recovery from hip fracture in eight areas of function. J Gerontol Ser A Biol Med Sci. 2000;55(9):M498-507.

48. Johnell O, Kanis JA. An estimate of the worldwide prevalence, mortality and disability associated with hip fracture. Osteoporos Int. 2004;15(11):897-902.

\section{Publisher's Note}

Springer Nature remains neutral with regard to jurisdictional claims in published maps and institutional affiliations.
Ready to submit your research? Choose BMC and benefit from:

- fast, convenient online submission

- thorough peer review by experienced researchers in your field

- rapid publication on acceptance

- support for research data, including large and complex data types

- gold Open Access which fosters wider collaboration and increased citations

- maximum visibility for your research: over $100 \mathrm{M}$ website views per year

At BMC, research is always in progress.

Learn more biomedcentral.com/submissions 